three distinct perforatious had formed in different parts of the surface of the abdomen.

We have seen that in Newman the probe used to pass in a straight direction for several inches within the bowel, which was very sensitive to its touch, so that, although sometimes blocked up, the ingesta, on the whole, have passed readily onwards, and very little medicine has been necessary on account of any obstruction. But suppose there is any sudden turn of the bowel, or contraction of the cicatrix, after the ulcer and artificial anus have healed: the consequence, as you may imagine, will be fatal. It is, in fact, according to my experience, by far the most frequent species of what is called stricture of the rectum, and you have seen its effects in a woman who re. cently left the hospital, in whom I had to lay open very extensive sinuses, running in every direction in the nates, labia, and vagina; and it may take place in any part of the intestines in which ulcers of the mucous membrane have formed.

4. I was asked to see a gentleman, in conjunction with Dr. Bence Jones and Messrs. Bullock and Dodd, who had been long in ill health, including in his symptoms pain in the left side; six months before I saw him he began to suffer from habitual constipation, but for the preceding month the action of the bowels had been regular. There was an enormous gangrenous abscess of the left side, crepitating with air, from the trochanter nearly to the short ribs, with a small slough at one part, emitting a very offensive odour through it. I laid it open extensively, with a little temporary relief, but his strength was quite exhausted, and he. died two or three days afterwards. This abscess communicated with the descending colon by a sloughy opening of about three inches in length; the bowel below this was flaccid and empty, but above it was enormously distended, so that the diameter of the colon was nearly four inches, and the transverse colon had fallen down, as it were, from its weight of fæces, to the pubes, so that the small intestines were all seen between the stomach and colon, through the thin and elongated omentum. There was no disease of the mucous membrane, except at the opening, nor any inflammation of the peritonæeum; and although the bowel was too much destroyed to make it certain that there had not been a thickened stricture at some former period, yet the appearance of the part of the circumference of the bowel which remained, looked much more as if there had been simple ulceration, cicatrized and contracted probably at the time the constipation began, with a restoration of a passage of the freces downwards, in consequence of renewed ulceration a month before his death, but which at the same time allowed some freces to get into the cellular tissue, and produce the gangrenous abscess which $I$ found when called in to see him. 5. In this part of the intestinal canal, however, real stricture is very often found, and may lead to the same fæcal abscesses as simple ulceration of the mucous surface. The most extraordinary instance of this kind which $I$ have seen was in a lady, in whom there had been for a considerable time some discharge of fæcal matter from the bladder, mixed with the water. I examined the body with Mr. Keate and some other gentlemen, not having seen the case during life. A narrow stricture of the colon had ulcerated, so as to let the contents of the bowel above it escape into a circumscribed cavity of large size, formed by adhesions in the lower part of the abdomen, having the bladder and uterus below, and the abdominal muscles and peritonæum in front. Ulceration had taken place from this cavity, so that its frecal contents passed in part into the bladder, and an opening had also formed in the lower part of the sigmoid flexure below the stricture; so that fæces had gone in this circuitous course through the cavity thus formed, into the rectum, without going through the stricture. Besides this, the abdominal parietes had been perforated in two places, so that in one place a large fæcal abscess existed below the external oblique muscle, and through the other aperture an enormous foul abscess, nearly gangrenous from the presence of frecs, distended the skin from the inguinal region to the axilla.

6. More often, as you might expect, mischief of this kind takes place in the cæcum on the right side of the body, the form of this part allowing of the lodgment of foces, particularly if there is a plum-stone, or other solid body, to form the nucleus of a mass, which may attain a considerable size. You will not unfrequently see a tumour thus formed in women, particularly after pregnancy, and lasting many years, varying in size according to the freedom with which the bowels act naturally or by purgatives, and sometimes cansing pain and tenderness when larger than usual, even when it stops short of ulceration. A collection of fæeces thus formed in the cæcum and lower part of the colon appears like a solid tumour, which is sometimes partly movable, though fixed at its base, and may appear like an ovarium, or other tumour; and, on the other hand, other bodies may occupy nearly the same situation. I was asked, some years ago, to see a lady, with Sir Benjamin Brodie, who had long had a solid body in this situation, which gave her at that time the pain and tenderness which an obstructed colon will occasion; but it proved that a large stone, formed in the right kidney, had drawn that body down, as it were, so as to be perceptible through the abdomen, and to interfere in some way with the bowel. The stone, $I$ believe, is in the nuseum at present.

7 . If a lodgment of freces causes irritation in the cxcum and colon, it produces ulceration, abscess, and artificial ants, or frecal abscess and gangrene. A singular and somewhat obscure case was under my care, about three years ago, in the hospital and when the patient died, some time after she left us, I had an opportunity, with Mr. Sharp, of examining the body. This woman had a solid elastic swelling in the right iliac fossa, and on the outside also of the ilium, so large that it gave one the idea of its being a carcinomatous growth of that bone, likely soon to be fatal, from the emaciation and suffering it had caused; this opinion seemed to be confirmed by the appearance of a round, solid body, the size of an orange, not far from, though not apparently attached to, the liver. After a time, swelling took place in the loins, and an abscess formed, which $I$ opened at the back of the ilium, so that I began to think I must be mistaken, and that there was perhaps a lumbar and psoas abscess, with caries of the spine. The disease, however proved, after her death, to have been an abscess communicating with the ascending colon and creum by an opening of several inches in length, and an immense collection, of several pounds weight, of a paste-like consistence and dark colour, existed in the loins and iliac fossa, formed obviously of freces, left in this situation, while the more fluid part had escaped, during many months. The round body felt in the abdomen was the upper end of the right kidney, which had been tilted forwards, in a curved form, by that part of the solid fæcal mass which filled the hollow of the lower ribs.

\section{ON A CASE OF THYMIC ASTHMA.}

\section{BY JOHN ARMSTRONG, M.D., M.R.C.S., \&c., Gravesend.}

ON Jan. 29th, 1851, Mrs M.-.-., residing in London, came to Gravesend with her child, aged five months, for change of air, by the advice of her medical attendant. A few days after their arrival I was requested to see him immediately, "as he had been seized with something like a fit." On my arrival, he had recovered, and was in his mother's arms, looking pale and frightened. He is a fine, well-formed child, with large head, not frontally prominent, fine skin, blue eyes, pallid countenance. I received the following history:-Three weeks prior to this, while out of doors, the child was suddenly seized with great difficulty of breathing, became almost livid in his countenance, and seemed as if he would be strangled before he could get his breath. Mrs. M- hastened home, plunged him into a hot bath, and sent for the nearest medical gentleman. When he arrived the child was better. He informed the mother that it was probably congestion of the lungs arising from exposure to the cold. He was placed under treatment, and after two or three days appeared better; still there was sickness and some difficulty of swallowing, and the child was sent down here for change of air.

The history of the present seizure was as follows:-He had been sleeping, roused up, began to fret, and made a peculiar noise; seemed as if he could not get his breath, and appeared going into a fit: it soon, however, passed away and the child appeared as usual. There had been, on some former occasions, some slight " child crowing," and also on this occasion. His bowels were correct; there was no constitutional disturbance; the gum covering the central lower incisors was swollen and hot, and was therefore lanced; some aperient and anti-spasmodic medicines were prescribed. He continued without any further seizure, and Mrs. M-, after about a week or ten days, returned to town. A few weeks after this, the child had a similar attack, though not so severe, apparently brought on by cold. The child was weaned when about eight months old, and was again taken down here. Some time after their arrival the child was attacked with symptoms of catarrh, which were slight, and were not considered sufficient to require medical attendance. After a few days (April 12th) he experienced another and more severe seizure than any former one and I was sent for in great haste. The history given was the following:- The child became suddenly dark about his mouth 
held his breath, his eyes seemed starting from their sockets, and his limbs became violently stretched. He appeared to recover his breath, began to cough, and when $I$ arrived the attack had passed away. He looked frightened; his face pale and bathed in perspiration; pulse weals, intermitting, and quickened; skin cold. There was considerable fulness of the veins of the neck; the chest resonant throughout; sibilus and rhonchi heard over the left lung, and partly the right; most distinctly heard on each side of the dorsal spine.

That night I was summoned to the little sufferer, who was stated to be dying. The attack was much the same; he had been sleeping, awoke up, became livid, convulsed, and apparently gasping for breath. I found him pale, with his head and face bathed in perspiration, with a feeble intermittent pulse, a loose frequent cough, troublesome at the termination of the attack. There had been no crowing respiration. The attacks of dyspncea now became frequent; he rarely went to sleep without an attack on awaking. They were now invariably accompanied with convulsions of an epileptic character. The countenance during the attack, lips especially, were quite livid, the tongue protruded, eyes turned in towards the nose, and nearly constant carpo-pedal contractions. The sides and centre of the lower part of the throat swollen, the jugular veins much distended; and the respiratory murmur was harsh or indistinct at the posterior part of the thorax. As each convulsive attack subsided, there was a peculiar, harsh, incessant, convulsive cough, by which small portions of frothy whitish phlegm were expelled from the trachea; and after some time about a teaspoonful or two was discharged, and the child seemed relieved. The dificulty of swallowing, especially of semi-fluid substances, continued, appearing always to excite coughing. Nothing gave relief; he continned to get worse, and died after an attack, on April 24th, about a fortnight after the catarrhal seizure.

Post-mortem examination sixteen hours after death.-In the examination of the body, the chest chiefly attracted attention. There was a large thymus gland, extending from the thyroid gland to the pericardium, and laterally filling the space between the trachea, clavicle, and first rib. It was dense, firm, lobnlated, of a fleshy colour; contained no fluid; it was upwards of an ounce in weiglit; its greatest density and development appeared on the left side; the large veins appeared almost flattened by the pressure; the par vagum and recurrent were pushed aside from their usual course, and must have been much pressed. The heart was of ordinary size, nearly empty. The foramen ovale closed. Internaliy the larynx and trachea were pale, except at the part where the thymus pressed, which was reddened; the remainder was natural, and without inflammatory appearances. The lungs, anteriorly, were natural; posteriorly, extensively carnified. Abdominal viscera healthy. The head was not examined.

Remarks. -This is the second case of this form of "laryngismus stridulus" which has occurred in my practice after a tolerably extensive acquaintance with infantile diseases for twenty years. The other was so similar in the essential characters both of the symptoms and post-mortem appearances, that after the above lengthened detail, $I$ feel it is unnecessary to give them.

It is obvious that I do not class the ordinary cases of laryngismus stridulus, as Grood has termed it, with the form under consideration. I have generally to treat cases of that form every year, which have been sent from London for change of air, (for I may, in passing, observe, that among the children of this healthy locality, the disease is almost unknown). The London children soon recover under the influence of fresh air, and such treatment as the case indicates. But the variety which Kopp has called thymic asthma, is a much more formidable affair. I am aware that there is great difference of opinion respecting the disease, some even denying that the enlarged thymus is the cause of such alarming symptoms, but the careful, truthful observations of so many persons must carry conviction to unprejudiced minds.

To Mr. Hood, of Kilmarnock, we are indebted for the first clear account of this formidable complaint, although Hassé, in his "Pathological Anatomy," says, "That Kopp first attempted to connect this preternatural enlargement of the thymus gland, and its pressure on the trachea, with an alarming ailment peculiar to childhood, which he accordingly terried thymic asthma." One cannot help feeling surprised at this error, as Hassé is obviously pretty well acquainted with Inglish medical literature, and Kopp himself, in his Essay, adverts to Hood's paper. In addition to the papers and cases by these gentlemen, we have some by Drs. Copland, Montgomery, and
West. This latter gentleman has observed one case, narrated in his very admirable "Lectures on the Diseases of Children," and which corresponds very exactly with the two cases observed by myself.

The conclusion is unavoidable, that though this form of the disease is very rare, yet that a most formidable and fatal disease is occasionally met with, dependent on enlarged thymus gland. That many of the symptoms exist in common with the ordinary forms of "laryngismus" is unquestionable, and therefore laryngismus stridulus must be considered as a generic term including several species. And, no doubt, by looking at the subject in this light, the discrepant opinions on this disease can be reconciled.

\section{The disease presents itself under three forms:-}

First. It occurs as a consequence of teething, intestinal irritation, worms, eruptions about the head, or it may be of a nervous or spasmodic character; and by suitable treatmentespecially change of air-is generally cured. Mr. Robertson, of Manchester, in the Medical Gazette, vol. viii., new series, has very clearly shown the benefit of change of air, and $\mathbf{I}$ fully agree with him; but we must not be misled by supposing that change of air is all that is requisite; so long as there are sources of irritation, the disease will probably go on till they are removed. I have been frequently consulted under such circumstances, and cases which had come here for change of air remained "in statu quo;" but as soon as the disordered function was rectified, the disease began to subside, and finally ceased. I could enumerate many cases of that description.

Second. The next class of cases are those which the late Dr. Hugh Ley so admirably portrayed; but although he threw much light on the subject, yet his views, it must be admitted, were too limited. He attributed these affections to enlarged bronchial and thyroid glands. Doubtless there are cases of this description-and bad cases they generally are-but I believe they do not occur so frequently as Dr. Ley supposed. Change of air, a healthy nurse, or suitable diet, close attention to the gums and bowels, and the administration of syrup of iodide of iron, will constitute the chief remedies.

Third. The last, most rare, and as I believe, the most formidable class, are those which have formed the subject of this paper, and the treatment of which is by no means settled. The first case I had was seen by my partner, the late $\mathrm{Mr}$. Park, of this town, and he took the views entertained by $\mathrm{Dr}$. John Clark as to the treatment. Accordingly, leeches and blisters were applied to the head, and mercury was given freely; but the post-mortem examination gave no signs of head disease, and nought save the hardened, enlarged thymus was discovered to explain the distressing symptoms. Mrs. M-'s child was treated by constant attention to the gums and bowels, leeches and blisters in the region of the thymus, mercury and anti-spasmodics, but with scarcely any relief. My impression is, that occasional leeching on the upper part of the chest, with the application of iodine externally and internally; strict attention to every source of irritation, with view to its immediate removal; causing the child to lie with its head well raised during sleep; a healthy atmosphere, and light food, will constitute the treatment most likely to prove beneficial.

But although $I$ cannot point out any infallible mode of treatment, a few words on diagnosis may prove beneficial.

Dr. Copland, in his "Dictionary," says truly, "The diagnosis of enlarged thymus gland is a matter of importance, but of difficulty," and has ably pointed out the leadipg distinguishing features.

Those upon which I would place most reliance are, the sex of the child (males constitute by far the majority of those already reported); the pale, white, soft countenance; the permanent fulness about the upper part of the sternum, extending upwards nearly to the thyroidal region; an almost constant fulness of the veins of the neck, particularly after any effort, and very strongly evident for some time after an attack of dyspnoea; dulness on percussion over that part of the sternum; signs of congestion of the lungs, and from an early period difficulty of swallowing; the crowing sound is either entirely absent or very partial; the pulse is weak and intermittent; and there are copious perspirations over the head. These constitute a group of signs which enabled me to determine my case most clearly, and I have no doubt will afford unerring guidance to those who have never met the disease, in arriving at a correct diagnosis when any such arise in their practice.

Gravesend, 1851 . 